Review Article

\title{
Oxidative Stress, Neuroinflammation, and NADPH Oxidase: Implications in the Pathogenesis and Treatment of Alzheimer's Disease
}

\author{
Upasana Ganguly $\mathbb{D}^{\mathbb{D}},{ }^{1}$ Upinder Kaur $\mathbb{D}^{\mathrm{D}},{ }^{2}$ Sankha Shubhra Chakrabarti $\mathbb{D}{ }^{3}$

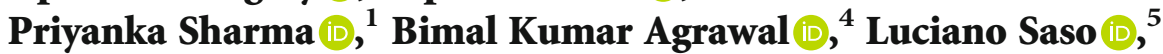 \\ and Sasanka Chakrabarti $\left.{ }^{1}\right)^{1}$ \\ ${ }^{1}$ Department of Biochemistry, MM Institute of Medical Sciences \& Research, Maharishi Markandeshwar Deemed University, \\ Mullana, Ambala, Haryana, India \\ ${ }^{2}$ Department of Pharmacology, Institute of Medical Sciences, Banaras Hindu University, Varanasi, India \\ ${ }^{3}$ Department of Geriatric Medicine, Institute of Medical Sciences, Banaras Hindu University, Varanasi, India \\ ${ }^{4}$ Department of General Medicine, MM Institute of Medical Sciences \& Research, Maharishi Markandeshwar Deemed University, \\ Mullana, Ambala, Haryana, India \\ ${ }^{5}$ Department of Physiology and Pharmacology "Vittorio Erspamer", Sapienza University of Rome, Rome, Italy
}

Correspondence should be addressed to Sasanka Chakrabarti; profschakrabarti95@gmail.com

Received 23 July 2020; Revised 17 March 2021; Accepted 3 April 2021; Published 17 April 2021

Academic Editor: Jos L. Quiles

Copyright (c) 2021 Upasana Ganguly et al. This is an open access article distributed under the Creative Commons Attribution License, which permits unrestricted use, distribution, and reproduction in any medium, provided the original work is properly cited.

\begin{abstract}
NADPH oxidase as an important source of intracellular reactive oxygen species (ROS) has gained enormous importance over the years, and the detailed structures of all the isoenzymes of the NADPH oxidase family and their regulation have been well explored. The enzyme has been implicated in a variety of diseases including neurodegenerative diseases. The present brief review examines the body of evidence that links NADPH oxidase with the genesis and progression of Alzheimer's disease (AD). In short, evidence suggests that microglial activation and inflammatory response in the AD brain is associated with increased production of ROS by microglial NADPH oxidase. Along with other inflammatory mediators, ROS take part in neuronal degeneration and enhance the microglial activation process. The review also evaluates the current state of NADPH oxidase inhibitors as potential diseasemodifying agents for AD.
\end{abstract}

\section{Introduction}

A review on oxidative stress and disease mechanisms and therapeutic use of antioxidants is usually not greeted with much enthusiasm, and reasons are not difficult to surmise. The story of oxidative stress and its involvement in multiple disease mechanisms and aging is quite old, spanning many decades [1]. However, a definitive evidence of oxidative stress as a driving mechanism of disease pathogenesis is still lacking. Likewise, inconsistent results of multiple clinical trials of antioxidants in various diseases, especially in neurodegenerative diseases, have been a cause for great disappointment to the advocates of free radical hypothesis of diseases [2-4].
On the other hand, there is a considerable body of experimental evidence that suggests the involvement of reactive oxygen species (ROS) and reactive nitrogen species (RNS), generally free radicals of oxygen and nitrogen, in the pathophysiology of many diseases and aging [4-6]. Thus, the free radical biology in health and disease has grown gradually over the years from the identification of various species of ROS and RNS in living systems and the elucidation of the chemistry and kinetics of their interactions to the identification of their toxic effects on different biomolecules and cell organelles $[7,8]$. Further, the enzymatic or nonenzymatic antioxidant defense system of the body and the redoxsignalling pathways regulating physiological and pathological 
processes within the cells have been identified $[7,9,10]$. The redox-signalling pathways play important roles in cell growth, differentiation, and death as evidenced from a plethora of experimental studies [10-12].

The antioxidant defense of the body generally counterbalances the various ROS and RNS in the normal physiological condition, but in pathological conditions when the free radicals overpower the antioxidant defense, a state of oxidative stress develops. It is presumable that direct damage to biomolecules within the cells by ROS and RNS and aberrant redox-signalling pathways together are involved in many diseases including neurodegenerative disorders $[5,6,13,14]$. The new technique of redox proteomics with the availability of antibodies against redox-modified proteins has strengthened our understanding of oxidative stress-induced mechanisms in diseases [15]. On the other hand, the identification of new antioxidants from natural sources or synthesis of novel, multifunctional, and organelle-targeted antioxidants has provided a new impetus in therapeutic applications of antioxidants [16-19]. So far, antioxidants have been developed with the precise aim of scavenging the free radicals of oxygen to prevent the deleterious effects of oxidative stress. Much less attempt has been made to prevent the generation of ROS at the source presumably because ROS are generated in most cases as a by-product of important metabolic pathways like the electron transport chain (ETC) of mitochondria which precludes the option of inhibiting the generation of ROS at the source. However, NADPH oxidase (NOX) is one enzyme whose sole function is the production of reactive oxygen species like superoxide radical $\left(\mathrm{O}_{2}{ }^{\bullet-}\right)$ and hydrogen peroxide, and therefore, inhibition of NOX could be an important rescue avenue against oxidative stress in tissues in different disease conditions. Thus, the therapeutic potential of NOX inhibitors should be explored thoroughly by experimental and clinical research.

\section{ROS and NADPH Oxidase}

2.1. Sources of ROS. The sources of ROS within the cells are varied, but they predominantly occur as a by-product of enzymatic reactions in different metabolic pathways. The ETC of mitochondria is a major contributor of intracellular ROS, but many other enzyme complexes in mitochondria like pyruvate dehydrogenase, $\alpha$-ketoglutarate dehydrogenase, cis-aconitase, glycerophosphate dehydrogenase, and dihydroorotate dehydrogenase are also responsible for ROS production [20-22]. Of the various complexes of ETC, complex I and complex III are the major sites of ROS production. The enzymes like cyclooxygenase, lipoxygenase, xanthine oxidase, and cytochrome P450-dependent oxygenases also contribute to ROS production [22]. Nonenzymatic or enzymatic oxidation of catecholamines and autoxidation of hemoglobin can also produce ROS under physiological conditions. However, another major source of ROS production is NOX, which was initially identified in neutrophils as the enzyme responsible for the production of superoxide radicals during a "respiratory burst" [23]. Since then, the biochemistry of NOX has been extensively studied, and this enzyme (in various isoforms) is present in a variety of tissues including the brain as well as in multiple cell lines. The NOX family of enzymes is comprised of 7 isoenzymes named as NOX15 and dual oxidases DUOX1 and DUOX2. NOX is responsible for the production of superoxide radicals $\left(\mathrm{O}_{2}{ }^{\bullet-}\right)$ by the transfer of electrons to molecular oxygen from NADPH via FAD and two heme residues of the enzyme. The $\mathrm{O}_{2}{ }^{\bullet-}$ radicals in turn undergo dismutation to produce $\mathrm{H}_{2} \mathrm{O}_{2}$, but it has been suggested that the isoenzymes NOX4, DUOX1, and DUOX2, could directly produce $\mathrm{H}_{2} \mathrm{O}_{2}[23,24]$.

2.2. NADPH Oxidase: Structure and Isozymes. Each of the seven members of the NOX family has a catalytic subunit comprised of a transmembrane domain of $6 \alpha$-helical segments containing two heme units liganded to histidine residues and a cytosolic segment which contains FAD and NADPH binding sites $[23,24]$. Additional structural features of the catalytic subunit are seen in some of the isoenzymes such as the EF-calcium-binding domains of NOX5, DUOX1, and DUOX2 and peroxidase domains of DUOX enzymes $[24,25]$. This large membrane-bound (plasma membrane and membranes of some organelles) subunit of NOX is associated with another membrane-bound protein called $\mathrm{p} 22^{\text {phox }}$ in some of the isoenzymes like NOX1, NOX2, NOX3, and NOX4, and the large heterodimer thus formed is called flavocytochrome b558. Likewise, the catalytic subunit of DUOX1 or DUOX2 is associated with another membrane-embedded protein called DUOXA1 or DUOXA2, respectively [24]. In addition, the NOX family of enzymes requires several other regulatory cytosolic proteins for activation, stability, or full function, and these additional interaction proteins are different for different isoenzymes [23, 24]. NOX2, which was the first isoenzyme to be identified in phagocytic cells, has been studied most, and its activation process may be taken as the prototype for other NOX family of enzymes. The catalytic subunit of NOX2 is known as gp9 ${ }^{\text {phox }}$ which remains in association with a membrane-embedded protein called $\mathrm{p} 22^{\text {phox }}$ which confers stability to the complex. During agonist activation, the cytosolic protein $\mathrm{p} 47^{\mathrm{phox}}$ is phosphorylated, which in association with some other cytosolic proteins called $\mathrm{p} 67^{\text {phox }}$ and $\mathrm{p} 40^{\text {phox }}$ and GTP-binding proteins like Rac2 and Rap1A translocates to the membrane to interact with the heterodimer of gp $91^{\text {phox }}$ and $\mathrm{p} 22^{\text {phox }}$ forming a fully functional enzyme. The interaction of src-homology domain $3(\mathrm{SH} 3)$ of $\mathrm{p} 47^{\text {phox }}$ with the C-terminal segment of $\mathrm{p} 22^{\mathrm{phox}}$, at a proline-rich sequence, is important in this assembly [23-25]. The detailed molecular interactions of these proteins during NOX2 activation and the functions of individual proteins have been identified. For example, p $47^{\text {phox }}$ is considered as an organizer protein without any catalytic property, while the activator protein $\mathrm{p} 67^{\text {phox }}$ increases the catalytic activity of NOX2. For some other NOX isoenzymes like NOX1, NOX3, and NOX4, a similar pattern of activation with some variations is seen with the aid of multiple regulatory proteins (activators or organizers) like NOXO1, NOXA1, PDI, and Poldip2, as well several GTP-binding proteins $[25,26]$. NOX5, DUOX1, and DUOX2, however, do not need any such assistance from other proteins, and they are presumably activated by the binding of $\mathrm{Ca}^{2+}$ ions at their cytosolic EF-calcium-binding domains [25, 26].

2.3. NADPH Oxidase: Physiological Role and Pathological Implications. In contrast to other sources, NOX is distinctive 
in producing ROS through a highly regulated complex enzymatic process and not as a by-product of a main reaction. Thus, the physiological role of NOX-dependent ROS production needs to be carefully analysed. In general, NOXdependent ROS takes part in redox-signalling pathways through redox-responsive signalling molecules (transcription factors, soluble or receptor-kinases, etc.), and the process regulates various aspects of cell growth, differentiation, survival, and metabolism with broad implications in immunity and inflammation, aging, cancer, and cardiovascular function and malfunctions [23, 24, 27-29]. For example, multiple studies have shown that vascular endothelial function and migration, angiogenesis, expression of cell adhesion molecules, vascular smooth muscle cell proliferation, etc. are regulated by multiple agonists like angiotensin II, growth factors, and cytokines through modulation of NADPH-dependent ROS production [28-30]. NOX-dependent ROS signalling is also involved in regulating cardiac remodelling, cardiomyocyte hypertrophy, and interstitial fibrosis after myocardial infarction or during chronic cardiac stress from hypertension [31]. The NOX4 isozyme, expressed in the mitochondria of cardiomyocytes, is particularly important in this context as has been shown in an experimental study; in heart-specific NOX4 knock-out mice, cardiac hypertrophy, interstitial fibrosis, mitochondrial dysfunction, and apoptosis of cardiomyocytes following pressure overload are significantly prevented compared to that in wild-type mice [32]. In cardiac-specific human NOX4 transgenic mice (hNOX4), a significant overexpression of NOX4 was observed with a high level of ROS production and associated myocardial fibrosis under basal condition when compared to littermate controls negative for hNOX4 [33]. This study further demonstrated that treatment with angiotensin II caused cardiac hypertrophy and myocardial fibrosis along with NOX4 upregulation and ROS production in control mice, and all these changes were much more aggravated in hNOX4 [33]. NOX4 in cardiomyocytes has been shown to be regulated by a tyrosine kinase belonging to Src-family [34].

NOX-generated ROS play an important role in tumor cell proliferation, metabolism, and progress. A systematic review has shown the association of lung cancer with increased expression and activity of NOX in tumor tissue and that inhibition of NOX could prevent tumor progression during in vitro experiments [35]. Similarly, overexpression of NOX2 has been reported in a significant number of human gastric carcinoma cases along with increased expression of EGFR and VEGF suggesting a biomarker potential of the former in this cancer [36]. Another study demonstrated a dysregulation of the expression of the NOX family of isoenzymes in human gastric cancer with overexpression of NOX2 indicating better prognosis and elevated NOX4 and decreased DUOX1 associated with worse outcome [37]. In other studies with human cancer tissue or cancer cell lines, the NOX family of isoenzymes is expressed differentially that probably has implications in tumor growth and invasion [38]. It is still debatable how exactly NOX regulates tumor growth and progression, but genomic instability caused by ROS, inactivation of p53 function, alterations in the functions of cell signalling kinases and phosphatases, and modu- lation of the functions of the ras oncogene may all be contributing to this process $[39,40]$. Another important function of NOX-mediated ROS is to modulate innate immunity and the inflammatory response. The role of NOX is well established in the respiratory burst of neutrophils, which is a component of innate immunity and a first-line defense against invading microbes. The other components of innate immunity involve pattern recognition receptors like membrane-bound toll-like receptors (TLRs) and several cytosolic receptors. These pattern recognition receptors respond to specific patterns in the bacterial proteins, DNA, peptidoglycan, lipopolysaccharide (LPS) etc. or DNA or RNA viruses and initiate multiple signalling mechanisms for host defense $[41,42]$. The involvement of NOX-derived ROS has been shown to be necessary for TLR-2-dependent innate immune response against Mycobacterium tuberculosis [43]. Similarly, NOX-dependent ROS generation is necessary for RIG-Imediated activation of the transcription factor IRF-3 leading to antiviral gene expression [44]. The transcription factor $\mathrm{NF}-\kappa \mathrm{B}$ is involved in the expression of multiple genes related to innate immunity, and bacterial LPS-induced activation of NF- $\kappa$ B through TLR-4 requires NOX-dependent ROS production [45]. Although NOX-mediated ROS production is important for host defense against microbial invasion, the role of NOX is possibly more complex. For example, influenza-Ainduced lung damage is aggravated by NOX2 isoenzymes, while DUOX2 isoenzymes are apparently protective [46]. Apart from influenza virus, other respiratory viruses like human respiratory syncytial virus and human rhinovirus may also cause increased ROS production by different isoenzymes of NOX, and despite the important role of NOX in host defense, NOX-derived ROS could aggravate lung inflammation and damage in many cases. Under such circumstances, the use of NOX inhibitors may become a potential therapeutic option $[46,47]$.

The role of oxidative damage in aging has been suggested many decades ago, and the original concept of progressive accumulation of oxidatively damaged biomolecules within cells with functional deterioration of tissues was quite straightforward [48, 49]. Thus, oxidative damage markers have been shown to accumulate in different tissues of aged animals in multiple studies, and ROS derived from mitochondrial metabolism and NOX have been both implicated in this process [48, 50-52]. The precise role of NOX in agerelated oxidative damage in brain has been shown using NOX2 knock-out mice or transgenic mice overexpressing NOX2 [53]. Age-dependent increase in NOX activity has been shown in the aged brain of rodents which is modulated by dietary manipulations [54, 55]. Likewise, NOX4 upregulation has been implicated in aging of heart [56]. However, most of these studies indicating a relationship of oxidative stress and aging in mammals are actually correlative in nature and do not necessarily identify a causal relationship. Moreover, this simple concept of generalized and indiscriminate ROSmediated damage to tissues as a pivotal mechanism of aging seemed contradictory when genetic manipulation studies overexpressing or knocking out antioxidant enzyme genes or environmental modifications in nematodes, flies, yeast, and other organisms revealed that complex interactions of 
ROS with life span extension genes instead of direct oxidative damage to tissue components are involved in aging and alteration of the life span of these species [57-61]. Both mitochondrial- and NOX-derived ROS at moderate levels are involved in actually increasing the longevity of these organisms by redox-signalling pathways, while presumably at higher levels of ROS, both oxidative damage and shortening of life span occur [59, 62-64]. However, the results of such life span alteration experiments on mammals by knocking out antioxidant enzyme genes or NOX have remained controversial, failing to show clearly the link between oxidative stress and longevity [65-68]. The redox-signalling pathways comprised of various redox-sensitive transcription factors and cell signalling kinases and their downstream components have also been identified and explored in detail in mammalian cells, but their precise role in mammalian aging at the organismal level has not been elucidated yet $[10,49,69]$.

2.4. NADPH Oxidase in the Brain. The vulnerability of the brain to oxidative damage is a well-accepted fact based on high oxygen consumption of the organ, availability of transition metals and autooxidizable catecholamines, abundance of polyunsaturated fatty acids, and the presence of a relatively weak antioxidant defense $[13,70]$. Oxidative stress is implicated in many diseases of the central nervous system (CNS); thus, NOX has been studied in a variety of pathological conditions of the brain $[71,72]$. The four NOX isoenzymes (NOX1, NOX2, NOX3, and NOX4) in the brain have been well explored in the context of brain development, aging and pathological conditions like ischemic or traumatic injury of the brain, neurodegenerative diseases, and different types of psychosis, but less information is available on NOX5 or the DUOX enzymes [72-76]. Although several early studies identified NOX2 in microglia, the inflammatory cells of the brain, many studies subsequently demonstrated the involvement of neuronal, astrocytic, or brain endothelial NOX in different conditions [72, 74, 75, 77]. NOX4 mRNA was shown to be overexpressed in neurons and newly formed capillaries in the brain in an experimental mouse model of ischemia, which persisted up to one month after the onset of ischemia [78]. Using a luminometric enzyme assay, NOX was also shown to be elevated in aged rat brain associated with increased accumulation of proinflammatory cytokines [55]. The age-dependent increase in ROS production and loss of neurons and capillaries in the brain of aged rats compared to young animals were shown to be significantly decreased in NOX2 knock-out rats [53]. In patients dying of traumatic brain injury (TBI), a selective increase in NOX2 was observed in parvalbumin-positive interneurons, but not in microglia, of postmortem brain without much changes in NOX1 and NOX4 isoenzymes as studied by immunohistochemistry [79].

NOX is also expressed in various primary cultures of neurons or neural stem cells or neural cell lines, and these have been manipulated genetically or pharmacologically to gain insight into normal or toxic functions of NOX-derived ROS in neurons. Thus, in primary culture of cerebellar granule cells, NOX is overexpressed in growth cones and filopodia with NOX-derived ROS involved in neuronal maturation [80]. Similarly, in primary culture of rat hippocampal neu- rons, genetic or pharmacological inactivation of NOX has been shown to cause altered neuronal polarization and inhibition of axonal growth [81]. In neural stem cells derived from mouse embryonic hippocampus, NOX inhibitors or ROS scavengers can inhibit cellular proliferation [82]. In neural crest stem cells, neuronal differentiation induced by bone morphogenetic protein 2 (BMP-2) in culture is regulated by NOX4 isoenzymes [83]. Likewise, nerve growth factor-induced differentiation of $\mathrm{PC} 12$ cells to a neuronal phenotype requires the presence of NADPH-dependent ROS [84]. Furthermore, NOX-dependent ROS have been suggested to play a crucial signalling role in long-term potentiation (LTP) and synaptic plasticity in several studies using pharmacological inhibition of NOX or by employing transgenic mice without functional NOX activity [85]. On the other hand, apoptosis of sympathetic neurons in culture under condition of nerve growth factor deprivation could be prevented by the inhibitor of NOX, suggesting a role of ROS in programmed cell death [86]. Overall, these studies indicate that ROS derived from NADPH oxidase are implicated in a multitude of signalling functions within neurons in normal conditions while their deleterious effects could be important in diseased conditions.

\subsection{Oxidative Stress, NADPH Oxidase, and Neurodegenerative} Diseases. Oxidative stress is an important element in the pathogenesis of many neurodegenerative diseases, where the deleterious actions of ROS on critical cellular components like proteins, phospholipids, and DNA could lead to the disruption and dysfunction of cell physiology which could be important in the genesis or progression of the disease [87-89]. The direct damage to cellular components by ROS has been extensively studied in vitro, and the pathways and end-products of proteins, phospholipids, and DNA oxidation have been elaborately identified forming a vast mass of literature on free radical biology [90-92]. The end-products of such oxidative damage pathways often accumulate in high amounts in many pathological conditions in the tissues and body fluids, which are measured as oxidative damage markers, and this is generally thought to be indicative of oxidative stress in pathological conditions. Thus, accumulation of phospholipid damage markers like malondialdehyde (MDA) or 4-hydroxynonenal (HNE) or F2 isoprostanes; protein damage markers like protein carbonyls and HNE protein adducts; or DNA damage markers like 8-hydroxydeoxyguanosine (8-OHdG) have been demonstrated in the brain, cerebrospinal fluid (CSF), and blood in many neurodegenerative diseases [93-97]. In contrast to such indiscriminate damage to cellular components by ROS, a regulated cell death process called ferroptosis has recently been identified, which is iron-dependent and requires ROS and lipid peroxidation products [98]. The morphological and biochemical characteristics of ferroptosis have been worked out, which appear to be different from apoptosis and necroptosis, and the process is triggered by a diverse group of molecules like erastin, sulphasalazine, BSO, DP12, DP17, cisplatin, and glutamate, many of which deplete the intracellular level of reduced glutathione (GSH) or inhibit glutathione peroxidase 4 (GPX4) [98, 99]. The biochemical features include increased production of ROS, accumulation of lipid 
peroxidation products, elevated intracellular level of iron, decreased glutathione level, and inhibition by iron-chelators and lipid-soluble antioxidants like $\alpha$-tocopherol, ferrostatin1 , and liproxstatin-1. The most characteristic morphological feature is the presence of deformed, shrunken mitochondria with loss of cristae and ruptured outer membrane and an intact nucleus [98-100]. The process of ferroptosis has been implicated in several pathological conditions like acute kidney injury, ischemia-reperfusion injury, cancer, and several neurodegenerative diseases $[98,100]$. In addition to these mechanisms, ROS have been shown to be involved both in apoptosis and regulated necrosis (necroptosis) in many experimental conditions, and this could be important in the context of neuronal death which is a hallmark feature of most neurodegenerative diseases [101-103].

Though the involvement of ROS in various cell death pathways is complex, contextual, and probably interrelated, it may be presumed that as a major contributor to intracellular ROS production, NOX would play an important role in cellular death pathways. Thus, enhanced NADPH oxidase activity has been reported in apoptosis and necroptosis in a variety of experimental models involving cardiomyocytes, pancreatic acinar cells, human aortic smooth muscle cells, endothelial cells, and fibroblasts [104-108]. In the context of neuronal death in $\mathrm{AD}$, we will discuss the role of NOX separately, but there is scattered evidence of NOX activation in other neurodegenerative diseases as well. Thus, postmortem brain studies have revealed high levels of NOX2 in the substantia nigra of sporadic Parkinson's disease (PD) patients, localizing with the microglial marker CD68 as evidenced by immunostaining [109]. In the same study, high levels of NOX2 in reactive microglia associated with dopaminergic neuronal loss have been observed in 1-methyl-4-phenyl1,2,3,6-tetrahydropyridine- (MPTP-) induced experimental models of $\mathrm{PD}$, and interestingly, much less dopaminergic neuronal loss is noticed in mice lacking NOX2 suggesting a clear link between neuronal death and NOX2 activation [109]. In another study of a 6-hydroxydopamine-based model of PD neurodegeneration in rats, increased expression levels of NOX1 and Rac1 (a component of the NOX1 complex) have been observed in dopaminergic neurons of the substantia nigra along with oxidative DNA damage and neuronal death which could be prevented significantly by knocking down the expression of NOX1 [110]. Oxidative stress and NOX have been implicated in the pathogenesis of another devastating neurodegenerative disease-amyotrophic lateral sclerosis (ALS) - in which progressive loss of motor neurons accompanied by gliosis occurs. In spinal cords of genetic mouse models of ALS, an increased expression of NOX2 has been demonstrated, and a similar increase has been observed in microglial NOX2 in postmortem spinal cord samples of ALS patients [111]. This study, however, has failed to show any improvement in the survival of ALS mouse models upon treatment with NOX inhibitors [111]. In an earlier study, mutant SOD1, as present in the familial type of ALS, expressed in human cell lines, was shown to activate NOX directly through the Racl regulator protein [112]. The aggregation and accumulation within neurons of mutant ATXN7 because of polyglutamine (poly-Q) expansion has been held responsible for the inherited neurodegenerative disease spinocerebellar ataxia type 7 (SCA7). In a cell-based model of this disease, the expression of mutant ATXN7 is accompanied by increased ROS production, aggregation of ATXN7, and cytotoxicity, which are preventable by a NOX inhibitor [113].

\subsection{Alzheimer's Disease, Oxidative Stress, and NOX}

2.6.1. Oxidative Stress in AD. Alzheimer's disease (AD) is characterized by a diffuse loss of neurons in the hippocampus, enterorhinal cortex, amygdala, and different regions of the neocortex with extracellular deposition of oligomerized amyloid beta peptide $(\mathrm{A} \beta 42)$ called amyloid plaques and intraneuronal neurofibrillary tangles composed of phosphorylated tau protein [13]. The disease causes progressive dementia and loss of multiple cognitive domains in a devastating form leading to death within 3-9 years of diagnosis. The accumulation of oxidative damage markers of lipids, proteins, and nucleic acids has been shown in multiple studies in CSF or postmortem brain tissue in $\mathrm{AD}$, and the topic is reviewed extensively [13, 87, 88, 93, 94, 114-117]. Such oxidative damage in the brain is also detectable in AD transgenic animals along with the deposition of amyloid plaques [118, 119]. In addition, the accumulation of transition metals like Fe and $\mathrm{Cu}$ in the $\mathrm{AD}$ brain has been shown in many postmortem studies using histochemical and magnetic resonance spectroscopic methods, but a meta-analysis subsequently has challenged this notion and suggested significant citation bias [120-123]. Antemortem imaging studies have also indicated iron accumulation in $\mathrm{AD}$ brains in several areas, but more extensive in vivo studies are necessary $[124,125]$. Although ROS can interact with any biomolecule within neurons, oxidative damage to proteins in particular could be important in $\mathrm{AD}$ pathogenesis through disruption of neuronal energy metabolism and proteostasis and aberrant redox signalling through activation of stress-activated protein kinases (JNK, p38, and ERK 1/2) or oxidative modifications of redox-sensitive transcription factors [126-128].

Most reviews dealing with oxidative damage in $\mathrm{AD}$ have discussed the reasons for enhanced ROS formation in the AD brain. In general, transition metal-catalysed ROS formation, especially with the metal liganded with $\mathrm{A} \beta$, could be an important contributor, and in addition, increased ROS formation can take place from dysfunctional mitochondria which is characteristic of $\mathrm{AD}$ [128-131]. On the other hand, the release of ROS from activated microglia as a part of the inflammatory response in the $\mathrm{AD}$ brain is also important, and NOX could be playing a crucial role in this process.

2.6.2. NADPH Oxidase and AD. NADPH oxidase activation has been strongly implicated in the pathogenesis of $\mathrm{AD}$ as evident from postmortem studies showing the translocation of NOX2 subunits $\mathrm{p} 47^{\text {phox }}$ and $\mathrm{p} 67^{\text {phox }}$ from cytosol to membrane, and this activation presumably takes place in activated microglia [132]. In another study, subjects were grouped on the basis of antemortem behavioural testing and postmortem histopathological assessment as no cognitive impairment (NCI), preclinical $\mathrm{AD}$, mild cognitive impairment (MCI), 


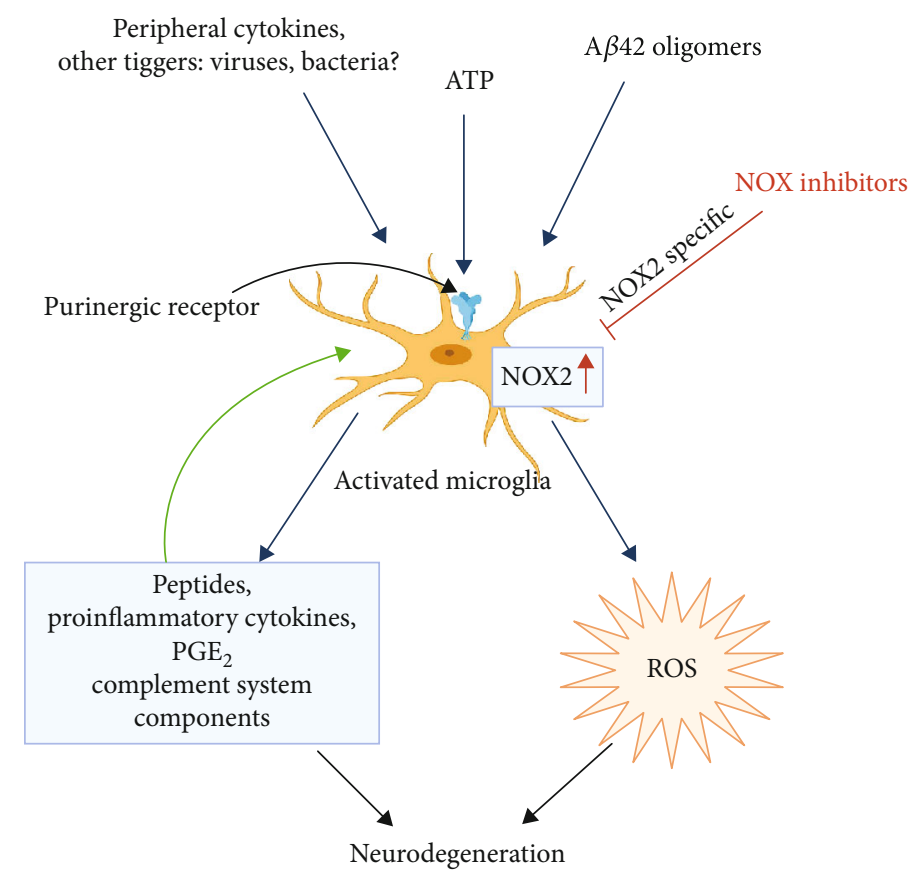

FIgURE 1: NOX activation in brain microglia in Alzheimer's disease. The microglial NOX2 is upregulated through multiple triggers including A $\beta 42$. Proinflammatory cytokines, chemokines, and NOX2-derived ROS act in concert to cause further activation of microglia and also neuronal damage linking inflammation and oxidative damage in AD pathology. The potential beneficial effects of NOX2 inhibitors have been indicated (image was created using BioRender).

and early to moderate AD; NOX activity was measured luminometrically, and protein expression levels of NOX2 subunits were assessed by immunoblotting [133]. The NOX enzyme activity was elevated in MCI, and different grades of AD compared to that in NCI. NOX2 subunit ( $\mathrm{p} 47^{\text {phox }}$, $\mathrm{p} 67^{\mathrm{phox}}$, and $\mathrm{p} 40^{\mathrm{phox}}$ ) levels also remained high in different grades of $\mathrm{AD}$, and in addition, a strong inverse correlation was observed with increased NOX activity associated with decreased cognitive functions [133]. In another longitudinal follow-up study of control subjects and patients of preclinical $\mathrm{AD}, \mathrm{MCI}$, and advanced $\mathrm{AD}$, increased NOX activity was seen in the temporal cortex of MCI patients but not in those of preclinical $\mathrm{AD}$ or advanced $\mathrm{AD}$ subjects; immunohistochemical and immunoblotting analyses showed increased levels of gp $91^{\text {phox }}$ and $\mathrm{p} 47^{\text {phox }}$ in the MCI group [134]. Further, this study showed that gp91 ${ }^{\text {phox }}$ was expressed in microglial cells as well as in neurons, and the toxic action of soluble oligomeric $\mathrm{A} \beta 42$ on neurons in culture were diminished by the NOX inhibitor apocynin [134]. The enhanced activity of NOX2 in AD may be caused by the activation of microglia by $\mathrm{A} \beta$ which releases ATP which in turn leads to NOX2 activation and ROS production; the process is mediated through the activation of the purinergic receptor $\mathrm{P} 2 \mathrm{X} 7$ and requires $\mathrm{Ca}^{2+}$ influx [135]. Another earlier study showed that microglia in primary culture stimulated by ATP acting through the purinergic receptor $\mathrm{P} 2 \mathrm{X} 7$ release superoxide radical $\left(\mathrm{O}_{2}{ }^{\bullet-}\right)$, and this process is mediated by NOX activation [136]. Furthermore, such activated microglia can lead to neuronal death in coculture suggesting a clear link among neuroinflammation, NOX activation, oxidative stress, and neurodegeneration [136]. Intracerebrovascular injection of LPS or $\mathrm{A} \beta$ oligomers causes an inflammatory response through the activation of microglia, but this response is inhibited in NOX-deficient $\left(\mathrm{p} 47^{\text {phox }}\right.$ or gp91 ${ }^{\text {phox }}$ deficient or apocynin treated) mice where the microglia attain the alternative phenotype (M2) responsible for tissue healing and repair [137]. Likewise, neuroblastoma cells with an overexpression of APP (wild-type or containing multiple mutations of familial AD) degenerate when cocultured with microglial cells because of ROS production by NOX, and this is expectedly attenuated by the NOX inhibitor DPI or radical scavengers [138].

In addition to NOX2, high levels of NOX1 and NOX3 mRNA have been observed in the frontal lobe of AD patients (early stages), indicating the contribution of other NOX isoforms in AD neuropathology [139]. The activity of NOX and the expression of the NOX4 subunit are also consistently elevated in the brain of APPxPS1 knock-in mice with a significant linear correlation between NOX activity and the age-dependent accumulation of $\mathrm{A} \beta$ with cognitive dysfunction [140]. On the other hand, transgenic mice (Tg2576) carrying human APP with the Swedish mutation and lacking in the catalytic subunit of NOX2 fail to develop oxidative damage, neurovascular dysfunction, and cognitive deficits at 12-15 months of age unlike $\mathrm{Tg} 2576$ mice with intact NOX2, though the brain amyloid beta burden in both the groups were similar [141]. Thus, a mounting body of evidence demonstrates NOX activation and ROS generation in the $\mathrm{AD}$ brain and primarily implicates microglial response as the trigger for increased ROS production. In the AD brain, soluble oligomers of amyloid beta peptide and other inflammatory triggers activate the microglia to M1 state with changes in morphology and exhibition of many inflammatory surface markers [128, 142, 143]. The microglia proliferate and assemble near the amyloid plaques releasing many 


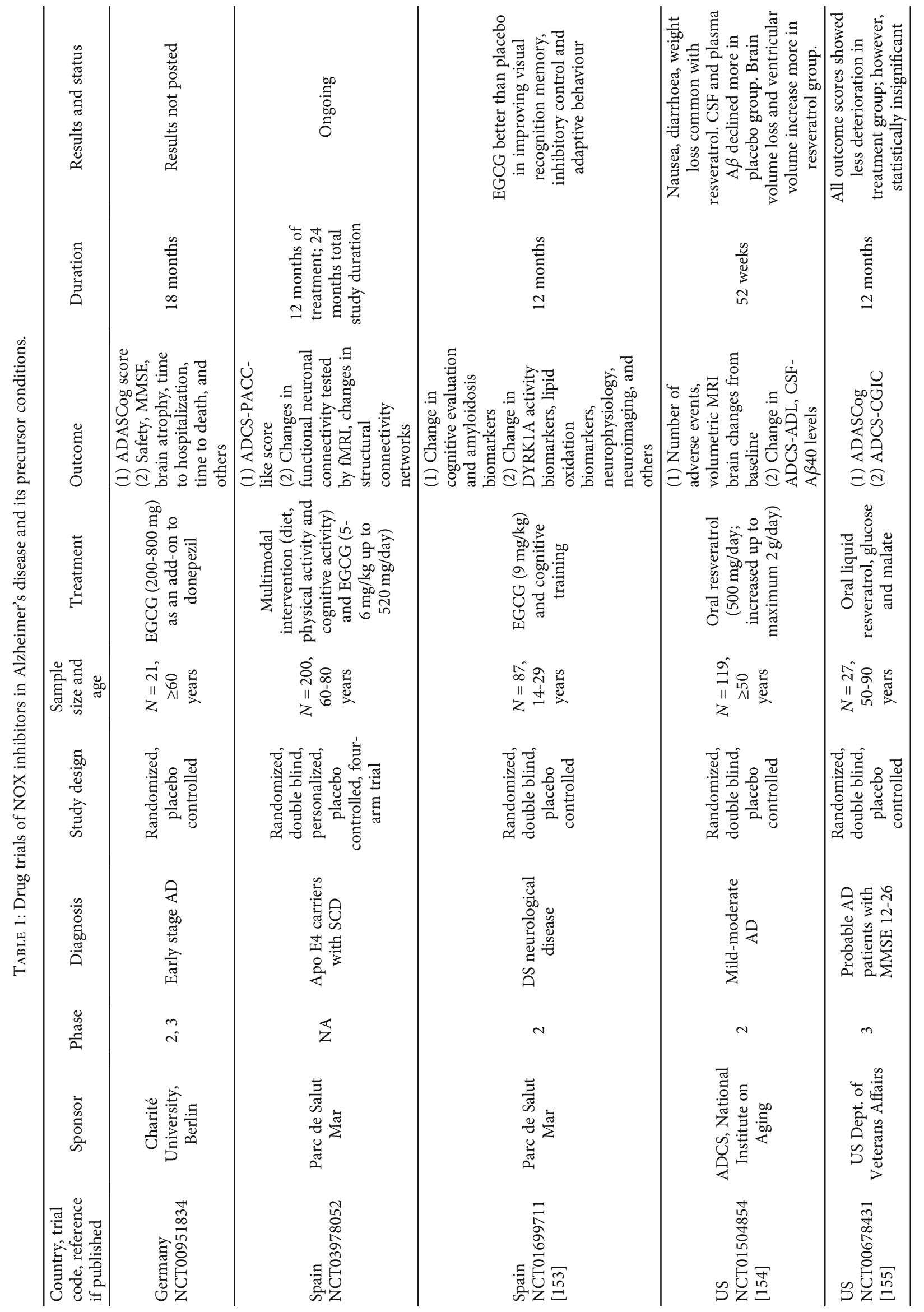




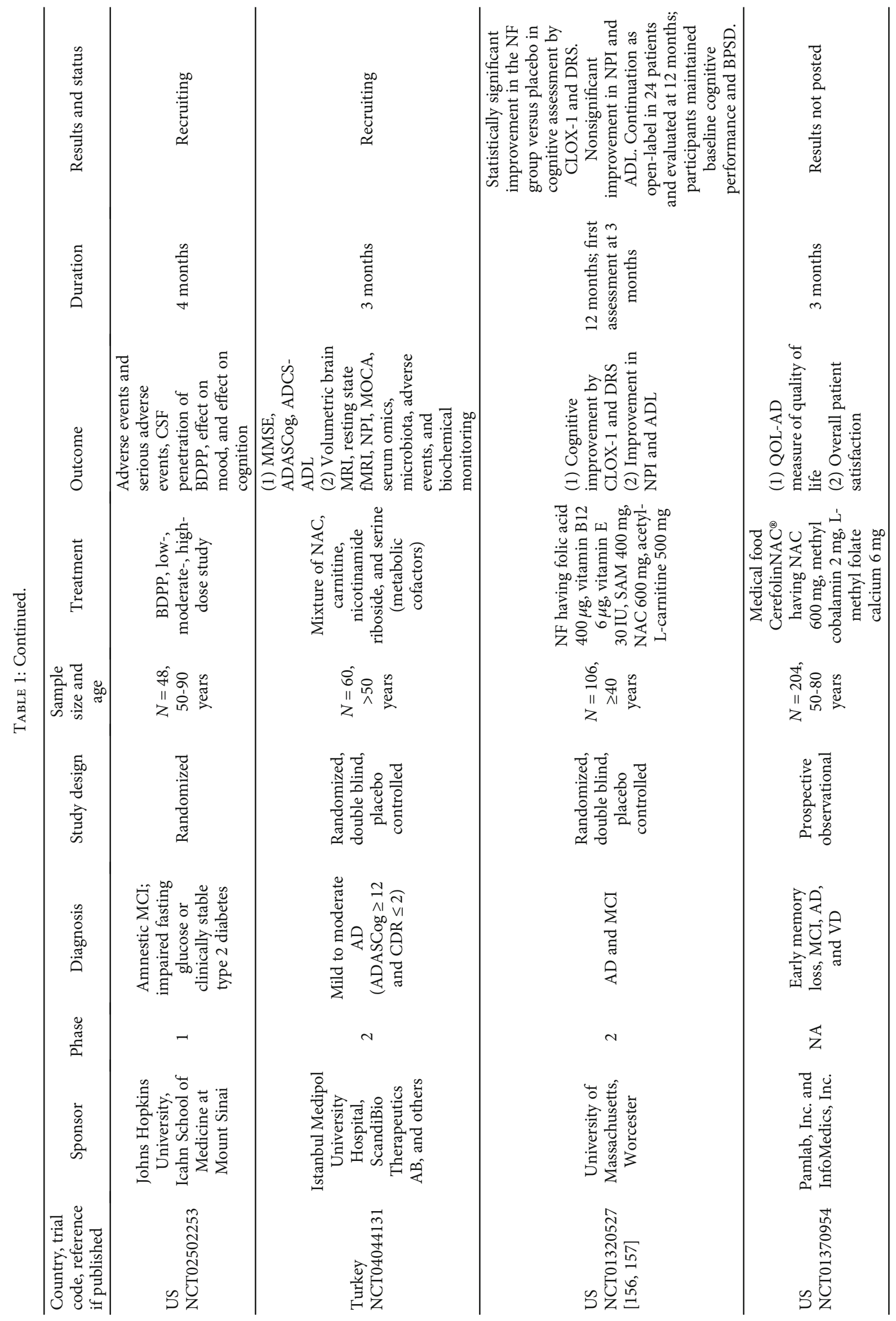




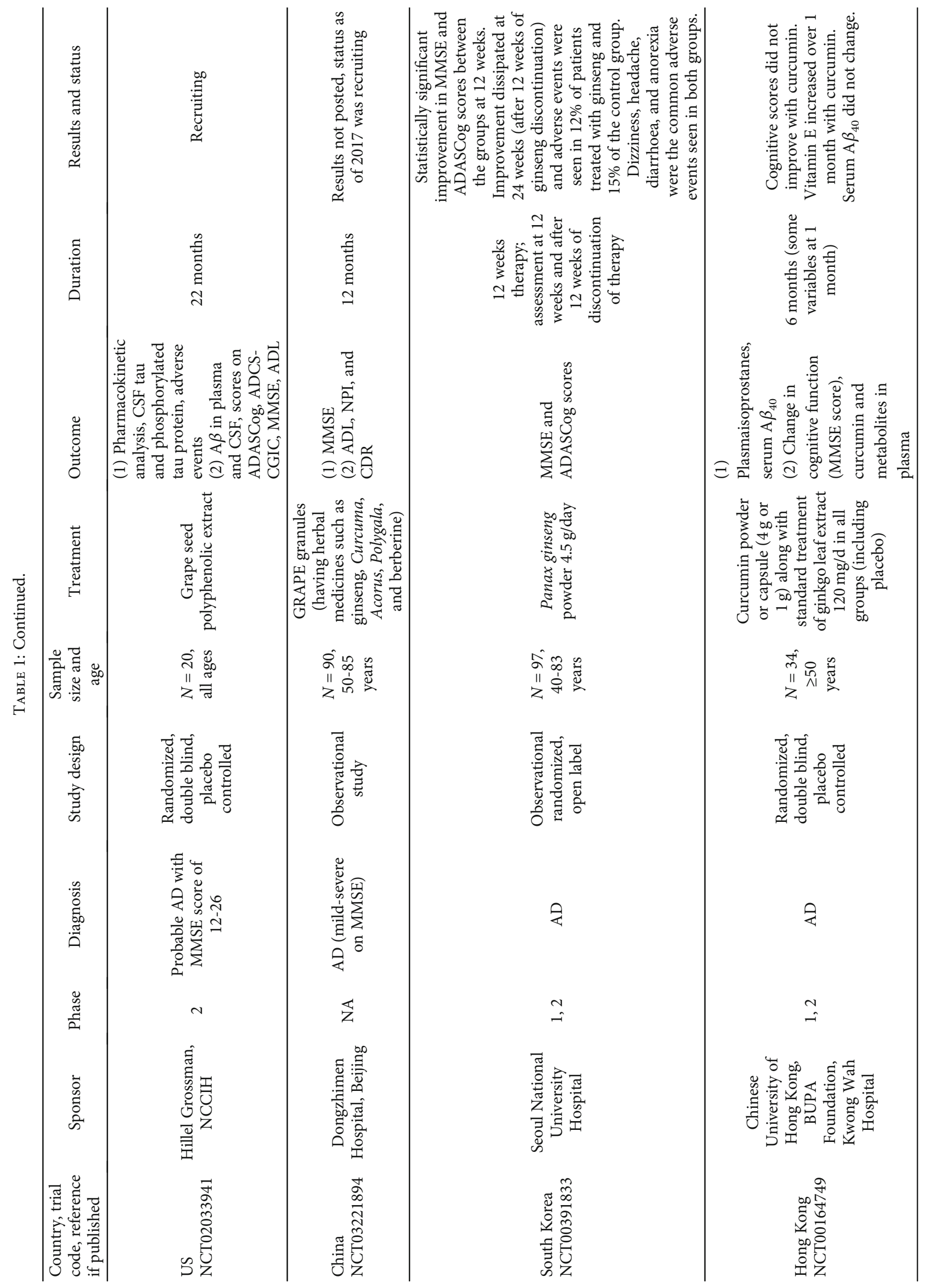




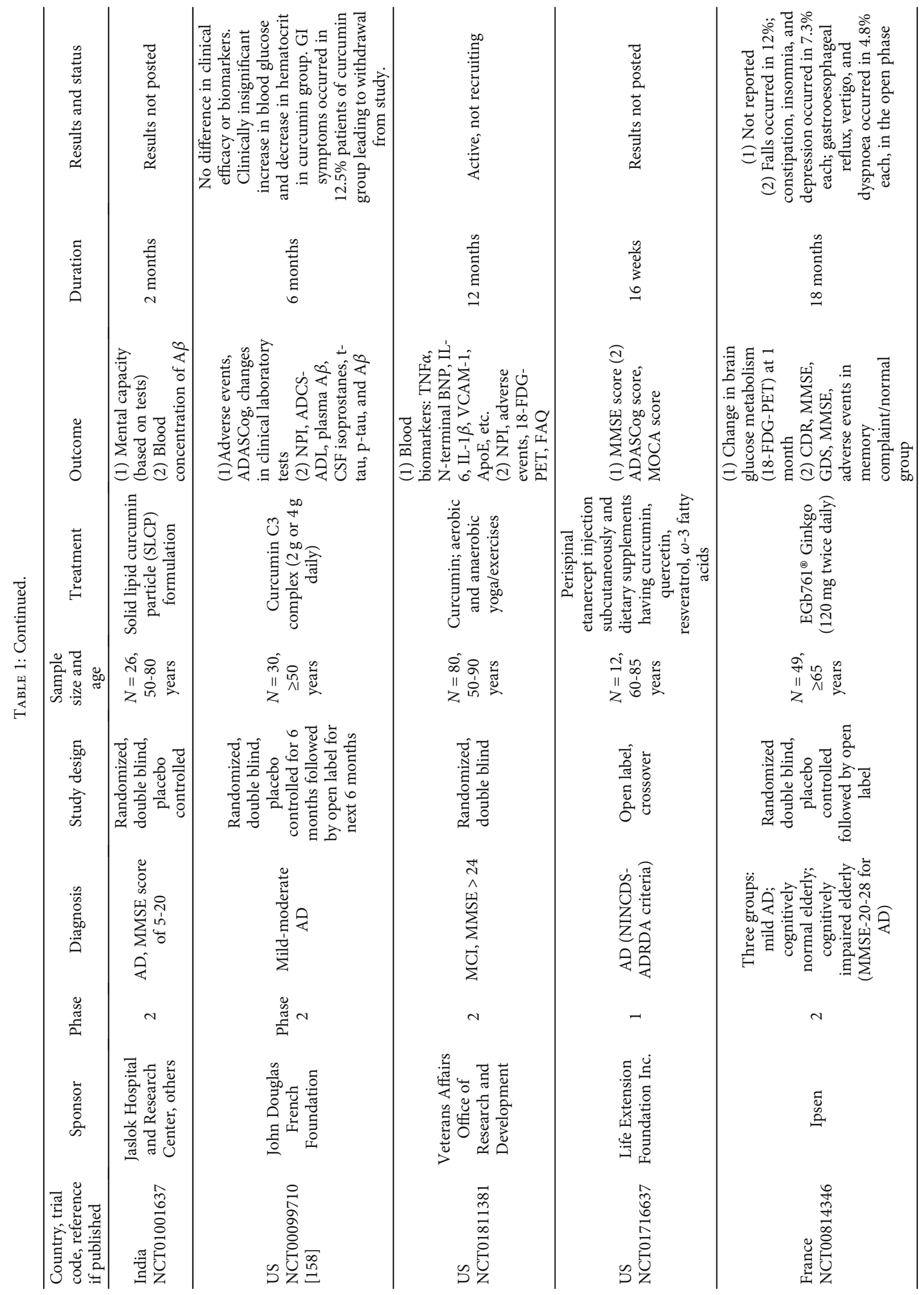




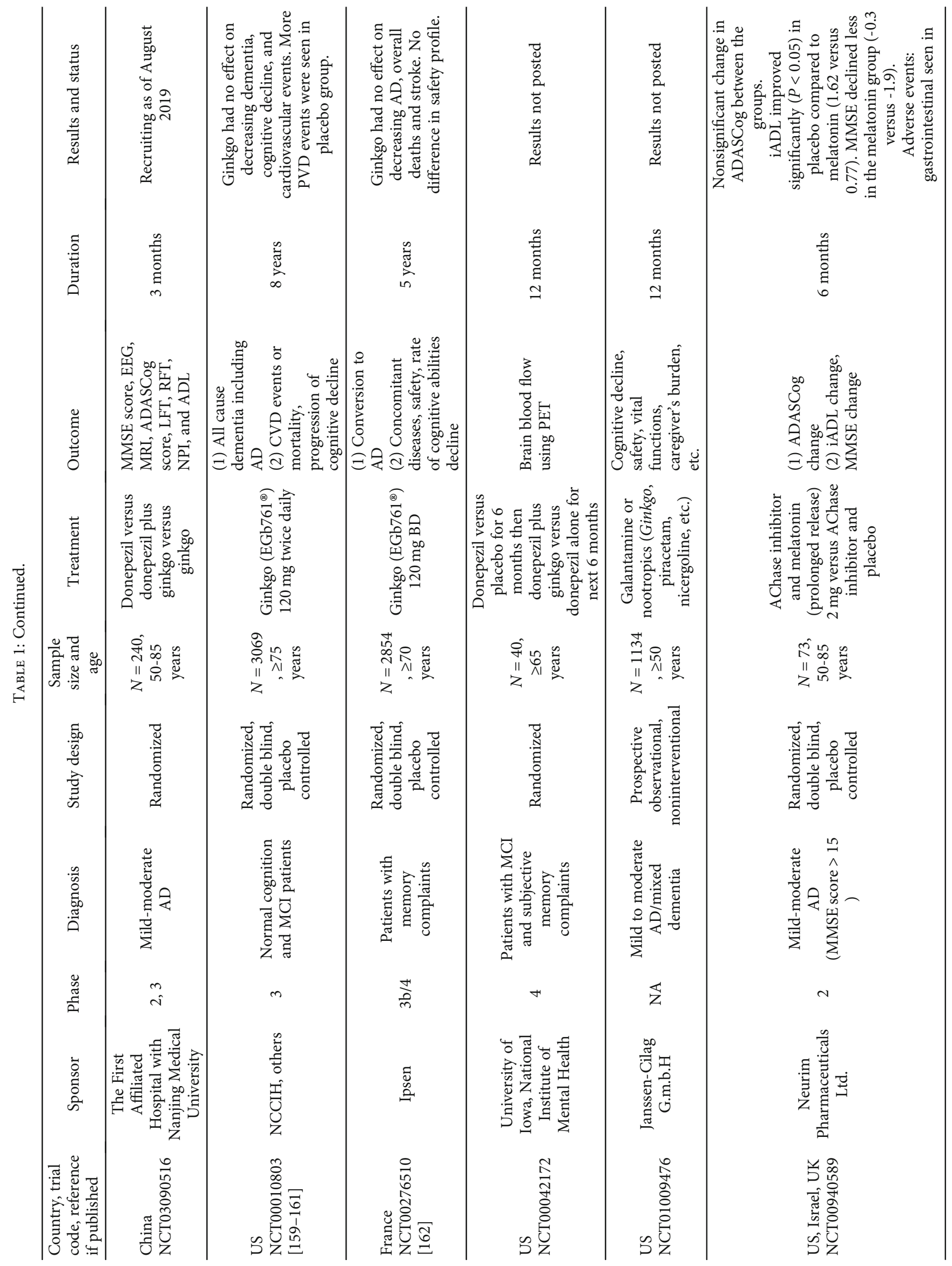




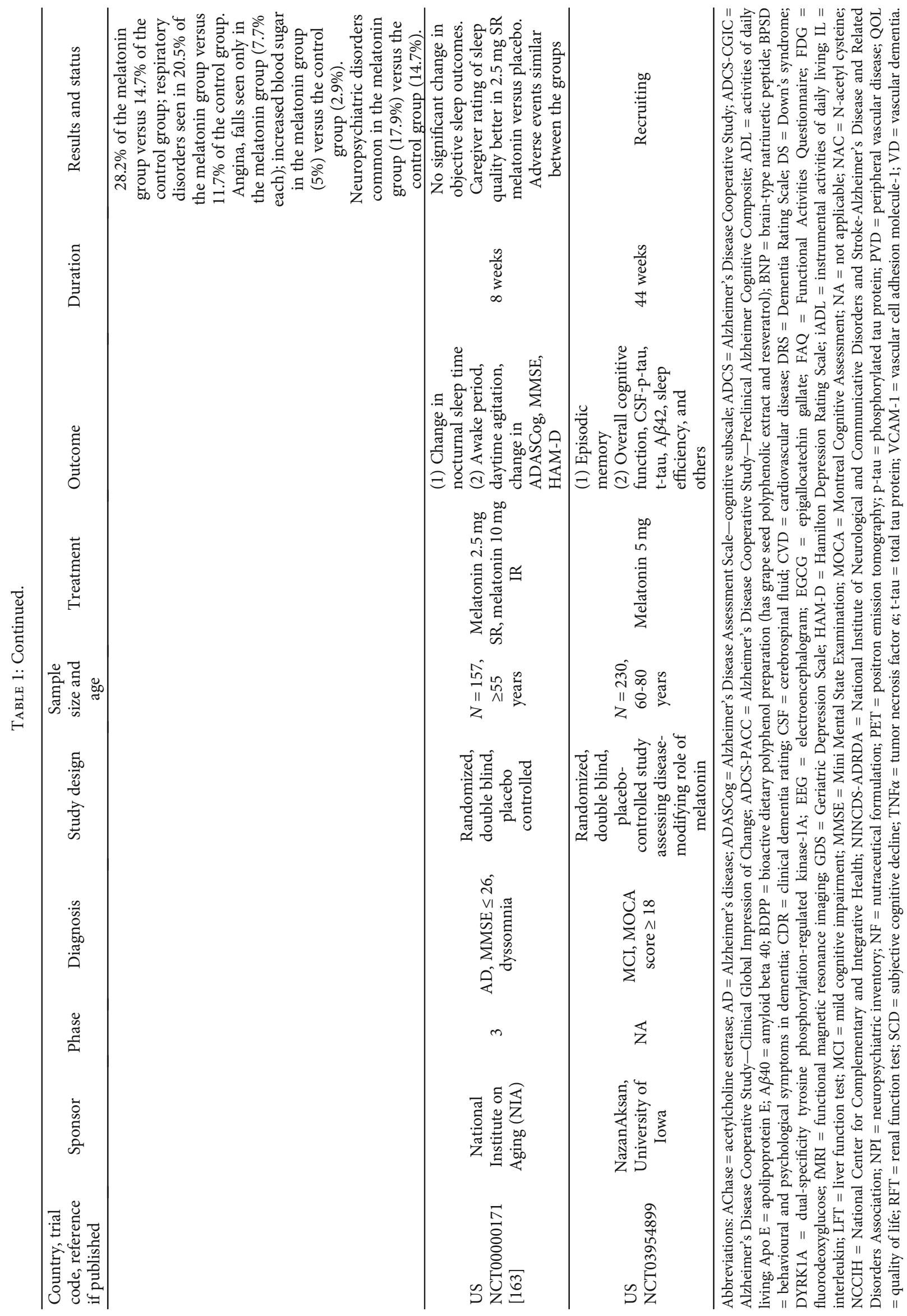


peptides, proinflammatory cytokines, chemokines, prostaglandins like $\mathrm{PGE}_{2}$, components of the complement system, and ROS, and thus a strong inflammatory response is generated which is partly responsible for neuronal and synaptic degeneration [128, 142-144]. The increased ROS production in reactive microglia occurs from activation of NOX2; ROS can cause degeneration of neurons and through redoxsignalling pathways enhance the formation and release of proinflammatory cytokines from the microglia [145]. This suggests an overlap of oxidative damage pathways, redoxsignalling mechanisms, and inflammatory response in $\mathrm{AD}$ brain. Figure 1 summarizes the mechanistic processes linked to NOX activation in microglia and the potential benefits of NOX2 inhibitors.

\section{NADPH Oxidase Inhibitors in AD}

It is apparent from the discussion above that NOX inhibitors will have substantial effects on the pathogenesis of $\mathrm{AD}$, attenuating both oxidative stress and neuroinflammation in the brain; thus, they are potential candidates as disease-modifying agents in $\mathrm{AD}$. Furthermore, NOX2, present predominantly in microglia, appears to be the most important isoenzyme involved in AD pathogenesis; thus, a specific inhibitor of NOX2 instead of a general NOX inhibitor could be even more effective. The NOX inhibitors are comprised of a heterogeneous group of molecules that include both peptide inhibitors and small molecule inhibitors. The peptide inhibitors are designed to prevent the binding of cytosolic accessory proteins to the membrane-bound catalytic portion of NOX; thus, they act as specific inhibitors of different isoenzymes of NOX (NOX2-ds-TAT and NoxA1ds are specific for NOX2 and NOX1, respectively) [146]. Many small-molecule inhibitors of NOX are currently available for research applications, and some of them are also being tested in clinical trials [146-148].

The classification of NOX inhibitors is complex. The older generation of small molecule NOX inhibitors include diphenylene iodonium (DPI) and apocynin, and the relatively less tested 4-(2-aminoethyl)-benzenesulphonyl fluoride (AEBSF) or plumbagin, while the more recently introduced compounds are GLX351322 and GSK2795039. A major issue with these drugs is the presence of additional actions such as direct ROS-scavenging properties, rho kinase inhibition, flavoprotein inhibition, and serine kinase inhibition. Many of them do not directly inhibit NOX but instead act on upstream triggers and downstream pathways of NOX $[26,148]$. Many of these drugs are not specific for any particular isoenzyme of NOX, but GKT137831 and GKT36901 are claimed to be specific for NOX1 and NOX4 [148]. This not only makes it difficult to judge how much their actual therapeutic benefits may be ascribed to NOX inhibition but also results in off-target effects, making clinical use difficult $[26,148]$. One drug that has been prominently tested, especially in a variety of cardiovascular disease states in animal models and some clinical trials is apocynin. It is a phenolic compound which is derived from the medicinal plant Jatropha multifida [149]. It has been also suggested that apocynin, which mainly inhibits NOX2, may have a benefi- cial role in Alzheimer's disease. A study investigating apocynin at an oral dose of $10 \mathrm{mg} / \mathrm{kg}$ daily in a hAPP (751) SL transgenic mouse model of $\mathrm{AD}$ found a significant reduction of plaque size within the cortex and hippocampus and a reduction of microglia number in the cortex [150]. In another experiment, male Wistar rats treated with scopolamine to induce an $\mathrm{AD}$ phenotype showed improvement in cognitive test performance when administered apocynin. This was accompanied by a decline in amyloid $\beta$ concentration in the rat hippocampi and a decrease in superoxide anion concentration [151]. Apart from the traditional small molecule inhibitors, several new agents such as GKT136901 and GKT137831; ML171; VAS2870 and VAS3947; S17834; Fulvene-5; the triphenylmethane derivative dyes, namely, imipramine blue, brilliant green, and Gentian violet; grindelic acid; ebselen; perhexiline; and Shionogi I and II have been proposed to have NOX-specific inhibitory activity based on experimental studies [26, 152]. Most of these agents, however, have not made it to the clinical trial stage, at least in neurodegenerative disorders. The focus of clinical studies in Alzheimer's disease thus remains on naturally obtained compounds with not only NOX inhibitory but also other beneficial effects. These include berberine, blueberryderived polyphenols, relatively NOX-specific celastrol, EGCG derived from green tea, Gingko biloba, resveratrol, and others. Table 1 summarizes several human studies of these agents in patients with Alzheimer's disease and its precursor states such as mild cognitive impairment [153-163]. It is evident that the results are quite variable, and hence, further studies are warranted to evaluate their role in $\mathrm{AD}$ therapeutics. It is also to be understood that NOXgenerated ROS take part in redox signalling under physiological conditions in the brain; thus, inhibition of NOX as a therapeutic measure may be fraught with additional problems.

\section{Conclusion}

The complexity of AD pathogenesis especially in sporadic cases precludes any "magic bullet" approach towards the therapy of this disease. Multiple disease-modifying drugs and multitargeted drugs could become important in the coming days to combat AD. To that extent, NOX inhibitors may provide an "add-on" therapy to maximize clinical benefit in $\mathrm{AD}$ treatment. However, a molecule specifically and directly inhibiting NOX2 without "off-target" effects would be necessary, and in addition, its bioavailability in the CNS and longterm toxicity have to be carefully evaluated.

\section{Data Availability}

This being a review article, no data was generated during the preparation of this manuscript.

\section{Conflicts of Interest}

The authors declare that there is no conflict of interest. 


\section{Acknowledgments}

SC and SSC want to thank the Indian Council of Medical Research, New Delhi, for their continued research support related to neurodegenerative diseases. SC and UG want to acknowledge the management of Maharishi Markandeshwar Deemed University for research and administrative support.

\section{References}

[1] D. Harman, "Free radical theory of aging: the "free radical" diseases," Age, vol. 7, no. 4, pp. 111-131, 1984.

[2] K. Goszcz, S. J. Deakin, G. G. Duthie, D. Stewart, S. J. Leslie, and I. L. Megson, "Antioxidants in cardiovascular therapy: panacea or false hope?," Frontiers in cardiovascular medicine, vol. 2, p. 29, 2015.

[3] M. Polidori and G. Nelles, "Antioxidant clinical trials in mild cognitive impairment and Alzheimer's disease-challenges and perspectives," Current Pharmaceutical Design, vol. 20, no. 18, pp. 3083-3092, 2014.

[4] G. H. Kim, J. E. Kim, S. J. Rhie, and S. Yoon, "The role of oxidative stress in neurodegenerative diseases," Experimental Neurobiology, vol. 24, no. 4, pp. 325-340, 2015.

[5] I. Liguori, G. Russo, F. Curcio et al., "Oxidative stress, aging, and diseases," Clinical Interventions in Aging, vol. 13, pp. 757-772, 2018.

[6] R. D'Oria, R. Schipani, A. Leonardini et al., "The role of oxidative stress in cardiac disease: from physiological response to injury factor," Oxidative Medicine and Cellular Longevity, vol. 2020, Article ID 5732956, 29 pages, 2020.

[7] B. Halliwell and J. M. Gutteridge, "Oxygen toxicity, oxygen radicals, transition metals and disease," Biochemical Journal, vol. 219, no. 1, pp. 1-14, 1984.

[8] H. Sies, C. Berndt, and D. P. Jones, "Oxidative stress," Annual Review of Biochemistry, vol. 86, no. 1, pp. 715-748, 2017.

[9] N. T. Moldogazieva, I. M. Mokhosoev, N. B. Feldman, and S. V. Lutsenko, "ROS and RNS signalling: adaptive redox switches through oxidative/nitrosative protein modifications," Free Radical Research, vol. 52, no. 5, pp. 507-543, 2018.

[10] M. Schieber and N. S. Chandel, "ROS function in redox signaling and oxidative stress," Current Biology, vol. 24, no. 10, pp. R453-R462, 2014.

[11] E. H. Sarsour, M. G. Kumar, L. Chaudhuri, A. L. Kalen, and P. C. Goswami, "Redox control of the cell cycle in health and disease," Antioxidants \& Redox Signaling, vol. 11, no. 12, pp. 2985-3011, 2009.

[12] B. W. L. Lee, P. Ghode, and D. S. T. Ong, "Redox regulation of cell state and fate," Redox Biology, vol. 25, 2019.

[13] S. Chakrabarti, M. Sinha, I. Thakurta, P. Banerjee, and M. Chattopadhyay, "Oxidative stress and amyloid beta toxicity in Alzheimer's disease: intervention in a complex relationship by antioxidants," Current Medicinal Chemistry, vol. 20, no. 37, pp. 4648-4664, 2013.

[14] A. H. K. Tsang and K. K. K. Chung, "Oxidative and nitrosative stress in Parkinson's disease," Biochimica et Biophysica Acta-Molecular Basis of Disease, vol. 1792, no. 7, pp. 643650, 2009.

[15] D. Allan Butterfield and I. Dalle-Donne, "Redox proteomics," Antioxidants \& Redox Signaling, vol. 17, no. 11, pp. 14871489, 2012.
[16] D.-P. Xu, Y. Li, X. Meng et al., "Natural antioxidants in foods and medicinal plants: extraction, assessment and resources," International Journal of Molecular Sciences, vol. 18, no. 1, p. 96, 2017.

[17] I. I. Severina, F. F. Severin, G. A. Korshunova et al., "In search of novel highly active mitochondria-targeted antioxidants: thymoquinone and its cationic derivatives," FEBS Letters, vol. 583, no. 13, pp. 2018-2024, 2013.

[18] H. H. Szeto, "Mitochondria-targeted peptide antioxidants: novel neuroprotective agents," The AAPS Journal, vol. 8, pp. 521-531, 2006.

[19] J. Wu, J. Ren, S. Yao et al., "Novel antioxidants' synthesis and their anti-oxidative activity through activating Nrf2 signaling pathway," Bioorganic \& Medicinal Chemistry Letters, vol. 27, no. 7, pp. 1616-1619, 2017.

[20] A. A. Starkov, "The role of mitochondria in reactive oxygen species metabolism and signaling," Annals of the New York Academy of Sciences, vol. 1147, no. 1, pp. 37-52, 2008.

[21] M. P. Murphy, "How mitochondria produce reactive oxygen species," Biochemical Journal, vol. 417, no. 1, pp. 1-13, 2008.

[22] N. Speed and I. A. Blair, "Cyclooxygenase- and lipoxygenasemediated DNA damage," Cancer and Metastasis Reviews, vol. 30, no. 3-4, pp. 437-447, 2011.

[23] A. Panday, M. K. Sahoo, D. Osorio, and S. Batra, "NADPH oxidases: an overview from structure to innate immunityassociated pathologies," Cellular \& Molecular Immunology, vol. 12, no. 1, pp. 5-23, 2015.

[24] J. L. Meitzler, S. Antony, Y. Wu et al., "NADPH oxidases: a perspective on reactive oxygen species production in tumor biology," Antioxidants \& Redox Signaling, vol. 20, no. 17, pp. 2873-2889, 2014.

[25] W. M. Nauseef, "Biological Roles for the NOX Family NADPH Oxidases," Journal of Biological Chemistry, vol. 283, no. 25, pp. 16961-16965, 2008.

[26] S. Altenhöfer, K. A. Radermacher, P. W. M. Kleikers, K. Wingler, and H. H. H. W. Schmidt, "Evolution of NADPH oxidase inhibitors: selectivity and mechanisms for target engagement," Antioxidants \& Redox Signaling, vol. 23, no. 5, pp. 406-427, 2015.

[27] I. Lorenzen, L. Mullen, S. Bekeschus, and E. M. Hanschmann, "Redox regulation of inflammatory processes is enzymatically controlled," Oxidative Medicine and Cellular Longevity, vol. 2017, Article ID 8459402, 23 pages, 2017.

[28] R. S. Frey, M. Ushio-Fukai, and A. B. Malik, "NADPH oxidase-dependent signaling in endothelial cells: role in physiology and pathophysiology," Antioxidants \& Redox Signaling, vol. 11, no. 4, pp. 791-810, 2009.

[29] R. Prieto-Bermejo and A. Hernández-Hernández, "The importance of NADPH oxidases and redox signaling in angiogenesis," Antioxidants, vol. 6, no. 2, 2017.

[30] A. Konior, A. Schramm, M. Czesnikiewicz-Guzik, and T. J. Guzik, "NADPH oxidases in vascular pathology," Antioxidants \& Redox Signaling, vol. 20, no. 17, pp. 2794-2814, 2014.

[31] C. E. Murdoch, M. Zhang, A. C. Cave, and A. M. Shah, "NADPH oxidase-dependent redox signalling in cardiac hypertrophy, remodelling and failure," Cardiovascular Research, vol. 71, no. 2, pp. 208-215, 2006.

[32] J. Kuroda, T. Ago, S. Matsushima, P. Zhai, M. D. Schneider, and J. Sadoshima, "NADPH oxidase 4 (Nox4) is a major source of oxidative stress in the failing heart," PNAS, vol. 107, no. 35 , pp. 15565-15570, 2010. 
[33] Q. D. Zhao, S. Viswanadhapalli, P. Williams et al., "NADPH oxidase 4 induces cardiac fibrosis and hypertrophy through activating Akt/mTOR and NF $\kappa$ B signaling pathways," Circulation, vol. 131, no. 7, pp. 643-655, 2015.

[34] S. Matsushima, J. Kuroda, P. Zhai et al., "Tyrosine kinase FYN negatively regulates NOX4 in cardiac remodeling," The Journal of Clinical Investigation, vol. 126, no. 9, pp. 3403-3416, 2016.

[35] M. Han, T. Zhang, L. Yang, Z. Wang, J. Ruan, and X. Chang, "Association between NADPH oxidase (NOX) and lung cancer: a systematic review and meta-analysis," Journal of Thoracic Disease, vol. 8, no. 7, pp. 1704-1711, 2016.

[36] P. Wang, Q. Shi, W. H. Deng et al., "Relationship between expression of NADPH oxidase 2 and invasion and prognosis of human gastric cancer," World Journal of Gastroenterology, vol. 21, no. 20, pp. 6271-6279, 2015.

[37] X. You, M. Ma, G. Hou, Y. Hu, and X. Shi, "Gene expression and prognosis of NOX family members in gastric cancer," OncoTargets Therapy, vol. 11, pp. 3065-3074, 2018.

[38] A. Juhasz, Y. Ge, S. Markel et al., "Expression of NADPH oxidase homologues and accessory genes in human cancer cell lines, tumours and adjacent normal tissues," Free Radical Research, vol. 43, no. 6, pp. 523-532, 2009.

[39] M. Skonieczna, T. Hejmo, A. Poterala-Hejmo, A. CieslarPobuda, and R. J. Buldak, "NADPH oxidases: insights into selected functions and mechanisms of action in cancer and stem cells," Oxidative Medicine and Cellular Longevity, vol. 2017, Article ID 9420539, 15 pages, 2017.

[40] T. Kamata, "Roles of Nox1 and other Nox isoforms in cancer development," Cancer Science, vol. 100, no. 8, pp. 1382-1388, 2009.

[41] O. Takeuchi and S. Akira, "Innate immunity to virus infection," Immunological Reviews, vol. 227, no. 1, pp. 75-86, 2009.

[42] B. Albiger, S. Dahlberg, B. Henriques-Normark, and S. Normark, "Role of the innate immune system in host defence against bacterial infections: focus on the Toll-like receptors," Journal of Internal Medicine, vol. 261, no. 6, pp. 511-528, 2007.

[43] C.-S. Yang, D.-M. Shin, K.-H. Kim et al., "NADPH oxidase 2 interaction with TLR2 is required for efficient innate immune responses to Mycobacteria via cathelicidin expression," The Journal of Immunology, vol. 182, no. 6, pp. 3696-3705, 2009.

[44] A. Soucy-Faulkner, E. Mukawera, K. Fink et al., "Requirement of NOX2 and reactive oxygen species for efficient RIG-I-mediated antiviral response through regulation of MAVS expression," Plos Pathogens, vol. 6, no. 6, 2010.

[45] H. S. Park, H. Y. Jung, E. Y. Park, J. Kim, W. J. Lee, and Y. S. Bae, "Cutting edge: direct interaction of TLR4 with $\mathrm{NAD}(\mathrm{P}) \mathrm{H}$ oxidase 4 isozyme is essential for lipopolysaccharide-induced production of reactive oxygen species and activation of NF- $\kappa \mathrm{B}$," The Journal of Immunology, vol. 173, no. 6, pp. 3589-3593, 2004.

[46] O. Khomich, S. Kochetkov, B. Bartosch, and A. Ivanov, "Redox biology of respiratory viral infections," Viruses, vol. 10, no. 8, p. 392, 2018.

[47] R. Vlahos and S. Selemidis, "NADPH oxidases as novel Pharmacologic targets against influenza A virus infection," Molecular Pharmacology, vol. 86, no. 6, pp. 747-759, 2014.

[48] D. Harman, "The aging process," PNAS, vol. 78, no. 11, pp. 7124-7128, 1981.
[49] K. C. Kregel and H. J. Zhang, "An integrated view of oxidative stress in aging: basic mechanisms, functional effects, and pathological considerations," American Journal of Physiology-Regulatory, Integrative and Comparative Physiology, vol. 292, no. 1, pp. R18-R36, 2007.

[50] K. H. Krause, "Aging: a revisited theory based on free radicals generated by NOX family NADPH oxidases," Experimental Gerontology, vol. 42, no. 4, pp. 256-262, 2007.

[51] Y. Shi, R. Buffenstein, D. A. Puliam, and H. V. Remmen, "Comparative studies of oxidative stress and mitochondrial function in aging," Integrative \& Comparative Biology, vol. 50, no. 5, pp. 869-879, 2010.

[52] M. Kasapoglu and T. Ozben, "Alterations of antioxidant enzymes and oxidative stress markers in aging," Experimental Gerontology, vol. 36, no. 2, pp. 209-220, 2001.

[53] L. M. Fan, L. Geng, S. Cahill-Smith et al., "Nox2 contributes to age-related oxidative damage to neurons and the cerebral vasculature," The Journal of Clinical Investigation, vol. 129, no. 8, pp. 3374-3386, 2019.

[54] A. J. Bruce-Keller, C. L. White, S. Gupta et al., "NOX activity in brain aging: exacerbation by high fat diet," Free Radical Biology and Medicine, vol. 49, no. 1, pp. 22-30, 2010.

[55] I. Guha Thakurta, M. Chattopadhyay, A. Ghosh, and S. Chakrabarti, "Dietary supplementation with $\mathrm{N}$-acetyl cysteine, $\alpha$-tocopherol and $\alpha$-lipoic acid reduces the extent of oxidative stress and proinflammatory state in aged rat brain," Biogerontology, vol. 13, no. 5, pp. 479-488, 2012.

[56] T. Ago, S. Matsushima, J. Kuroda, D. Zablocki, T. Kitazono, and J. Sadoshima, "The NADPH oxidase Nox4 and aging in the heart," Aging, vol. 2, no. 12, pp. 1012-1016, 2010.

[57] W. C. Orr and R. S. Sohal, "Extension of life-span by overexpression of superoxide dismutase and catalase in Drosophila melanogaster," Science, vol. 263, no. 5150, pp. 1128-1130, 1994.

[58] R. J. Mockett, W. C. Orr, J. J. Rahmandar et al., "Overexpression of Mn-Containing Superoxide Dismutase in Transgenic _Drosophila melanogaster_," Archives of Biochemistry and Biophysics, vol. 371, no. 2, pp. 260-269, 1999.

[59] G. N. Landis and J. Tower, "Superoxide dismutase evolution and life span regulation," Mechanisms of Ageing and Development, vol. 126, no. 3, pp. 365-379, 2005.

[60] R. J. Mockett, B. H. Sohal, and R. S. Sohal, "Expression of multiple copies of mitochondrially targeted catalase or genomic Mn superoxide dismutase transgenes does not extend the life span of Drosophila melanogaster," Free Radical Biology and Medicine, vol. 49, no. 12, pp. 2028-2031, 2010.

[61] V. M. Labunskyy and V. M. Gladyshev, "Role of reactive oxygen species-mediated signaling in aging," Antioxidants \& Redox Signaling, vol. 19, no. 12, pp. 1362-1372, 2013.

[62] A. Sanz, "Mitochondrial reactive oxygen species: do they extend or shorten animal lifespan?," Biochimica et Biophysica Acta - Bioenergetics, vol. 1857, no. 8, pp. 1116-1126, 2016.

[63] H. Sasakura, H. Moribe, M. Nakano, K. Ikemoto, K. Takeuchi, and I. Mori, "Lifespan extension by peroxidase and dual oxidase-mediated ROS signaling through pyrroloquinoline quinone in C. elegans," Journal of Cell Science, vol. 130, no. 15, pp. 2631-2643, 2017.

[64] C. Y. Ewald, J. M. Hourihan, M. S. Bland et al., "NADPH oxidase-mediated redox signaling promotes oxidative stress resistance and longevity through memo-1 in C. elegans," eLife, vol. 6, article e19493, 2017. 
[65] T. Schrader, C. Reschke, M. Spaeth, S. Wienstroer, S. Wong, and K. Schröder, "NoxO1 knockout promotes longevity in mice," Antioxidants, vol. 9, no. 3, p. 226, 2020.

[66] F. Rezende, C. Schürmann, S. Schütz et al., "Knock out of the NADPH oxidase Nox4 has no impact on life span in mice," Redox Biology, vol. 11, pp. 312-314, 2017.

[67] Y. Zhang, Y. Ikeno, W. Qi et al., "Mice deficient in both Mn superoxide dismutase and glutathione peroxidase- 1 have increased oxidative damage and a greater incidence of pathology but no reduction in longevity," The Journals of Gerontology, vol. 64A, no. 12, pp. 1212-1220, 2009.

[68] S. E. Schriner and N. J. Linford, "Extension of mouse lifespan by overexpression of catalase," Age, vol. 28, no. 2, pp. 209218, 2006.

[69] P. Davalli, T. Mitic, A. Caporali, A. Lauriola, and D. D'Arca, "ROS, cell senescence, and novel molecular mechanisms in aging and age-related diseases," Oxidative Medicine and Cellular Longevity, vol. 2016, Article ID 3565127, 18 pages, 2016.

[70] J. N. Cobley, M. L. Fiorello, and D. M. Bailey, "13 reasons why the brain is susceptible to oxidative stress," Redox Biology, vol. 15, pp. 490-503, 2018.

[71] M. Patel, "Targeting oxidative stress in central nervous system disorders," Trends in Pharmacological Sciences, vol. 37, no. 9, pp. 768-778, 2016.

[72] Z. Nayernia, V. Jaquet, and K. H. Krause, "New insights on NOX enzymes in the central nervous system," Antioxidants \& Redox Signaling, vol. 20, no. 17, pp. 2815-2837, 2014.

[73] S. J. Cooney, S. L. Bermudez-Sabogal, and K. L. Byrnes, “Cellular and temporal expression of NADPH oxidase (NOX) isotypes after brain injury," Journal of Neuroinflammation, vol. 10, no. 1, 2013.

[74] C. Angeloni, C. Prata, F. V. D. Sega, R. Piperno, and S. Hrelia, "Traumatic brain injury and NADPH oxidase: a deep relationship," Oxidative Medicine and Cellular Longevity, vol. 2015, Article ID 370312, 10 pages, 2015.

[75] M. W. Ma, J. Wang, Q. Zhang et al., "NADPH oxidase in brain injury and neurodegenerative disorders," Molecular Neurodegeneration, vol. 12, no. 1, 2017.

[76] A. Tarafdar and G. Pula, "The role of NADPH oxidases and oxidative stress in neurodegenerative disorders," International Journal of Molecular Sciences, vol. 19, no. 12, p. 3824, 2018.

[77] S. Sorce and K. H. Krause, "NOX enzymes in the central nervous system: from signaling to disease," Antioxidants \& Redox Signaling, vol. 11, no. 10, pp. 2481-2504, 2009.

[78] P. Vallet, Y. Charnay, K. Steger et al., "Neuronal expression of the NADPH oxidase NOX4, and its regulation in mouse experimental brain ischemia," Neuroscience, vol. 132, no. 2, pp. 233-238, 2005.

[79] S. Schiavone, M. Neri, L. Trabace, and E. Turillazzi, "The NADPH oxidase NOX2 mediates loss of parvalbumin interneurons in traumatic brain injury: human autoptic immunohistochemical evidence," Scientific Reports, vol. 7, no. 1, p. 8752, 2017.

[80] M. Olguín-Albuerne and J. Morán, "ROS produced by NOX2 control in vitro development of cerebellar granule neurons development," ASN Neuro, vol. 7, no. 2, p. $175909141557871,2015$.

[81] C. Wilson, M. Tulio Núñez, and C. González-Billault, “Contribution of NADPH oxidase to the establishment of hippo- campal neuronal polarity in culture," Journal of Cell Science, vol. 128, no. 16, pp. 2989-2995, 2015.

[82] M. Yoneyama, K. Kawada, Y. Gotoh, T. Shiba, and K. Ogita, "Endogenous reactive oxygen species are essential for proliferation of neural stem/progenitor cells," Neurochemistry International, vol. 56, no. 6-7, pp. 74-746, 2010.

[83] J. E. Lee, K. E. Cho, K. E. Lee, J. Kim, and Y. S. Bae, "Nox4mediated cell signaling regulates differentiation and survival of neural crest stem cells," Molecules and Cells, vol. 37, no. 12, pp. 907-911, 2014.

[84] K. Suzukawa, K. Miura, J. Mitsushita et al., "Nerve growth factor-induced neuronal differentiation requires generation of Rac1-regulated reactive oxygen species," Journal of Biological Chemistry, vol. 275, no. 18, pp. 13175-13178, 2000.

[85] C. A. Massaad and E. Klann, "Reactive oxygen species in the regulation of synaptic plasticity and memory," Antioxidants \& Redox Signaling, vol. 14, no. 10, pp. 2013-2054, 2011.

[86] S. P. Tammariello, M. T. Quinn, and S. Estus, "NADPH oxidase contributes directly to oxidative stress and apoptosis in nerve growth factor-deprived sympathetic neurons," Journal of Neuroscience, vol. 20, no. 1, p. RC53, 2000.

[87] G. Ganguly, S. Chakrabarti, U. Chatterjee, and L. Saso, "Proteinopathy, oxidative stress and mitochondrial dysfunction: cross talk in Alzheimer's disease and Parkinson's disease," Drug Design Development and Therapy, vol. 11, pp. 797810, 2017.

[88] A. M. Swomley and D. A. Butterfield, "Oxidative stress in Alzheimer disease and mild cognitive impairment: evidence from human data provided by redox proteomics," Archives of Toxicology, vol. 89, no. 10, pp. 1669-1680, 2015.

[89] S. C. Barber, R. J. Mead, and P. J. Shaw, "Oxidative stress in ALS: a mechanism of neurodegeneration and a therapeutic target," Biochimica et Biophysica Acta (BBA) - Molecular Basis of Disease, vol. 1762, no. 11-12, pp. 1051-1067, 2006.

[90] E. Niki, Y. Yoshida, Y. Saito, and N. Noguchi, "Lipid peroxidation: mechanisms, inhibition, and biological effects," Biochemical and Biophysical Research Communications, vol. 338, no. 1, pp. 668-676, 2005.

[91] I. Marrocco, F. Altieri, and I. Peluso, "Measurement and clinical significance of biomarkers of oxidative stress in humans," Oxidative Medicine and Cellular Longevity, vol. 2017, Article ID 6501046, 32 pages, 2017.

[92] S. Loft and H. E. Poulsen, "Markers of oxidative damage to DNA: antioxidants and molecular damage," Methods in Enzymology, vol. 300, pp. 166-184, 1999.

[93] W. R. Markesbery and M. A. Lovell, "Four-Hydroxynonenal, a Product of Lipid Peroxidation, is Increased in the Brain in Alzheimer's Disease," Neurobiology of Aging, vol. 19, no. 1, pp. 33-36, 1998.

[94] D. A. Butterfield, M. Perluigi, and R. Sultana, "Oxidative stress in Alzheimer's disease brain: New insights from redox proteomics," European Journal of Pharmacology, vol. 545, no. 1 , pp. $39-50,2006$.

[95] K. Gmitterová, U. Heinemann, J. Gawinecka et al., "8-OHdG in cerebrospinal fluid as a marker of oxidative stress in various neurodegenerative diseases," Neurodegenerative Diseases, vol. 6, no. 5-6, pp. 263-269, 2009.

[96] D. T. Dexter, C. J. Carter, F. R. Wells et al., "Basal lipid peroxidation in substantia nigra is increased in Parkinson's disease," Journal of Neurochemistry, vol. 52, no. 2, pp. 381389, 1989. 
[97] K. S. Montine, J. F. Quinn, J. Zhang et al., "Isoprostanes and related products of lipid peroxidation in neurodegenerative diseases," Chemistry and Physics of Lipids, vol. 128, no. 1-2, pp. 117-124, 2004.

[98] C. Han, Y. Liu, R. Dai, N. Ismail, W. Su, and B. Li, "Ferroptosis and its potential role in human diseases," Frontiers in Pharmacology, vol. 11, no. 239, 2020.

[99] J. Li, F. Cao, H.-l. Yin et al., "Ferroptosis: past, present and future," Cell Death \& Disease, vol. 11, no. 2, p. 88, 2020.

[100] B. R. Stockwell, J. P. F. Angeli, H. Bayir et al., "Ferroptosis: a regulated cell death nexus linking metabolism, redox biology, and disease," Cell, vol. 171, no. 2, pp. 273-285, 2017.

[101] M. Redza-Dutordoir and D. A. Averill-Bates, "Activation of apoptosis signalling pathways by reactive oxygen species," Biochimica et Biophysica Acta (BBA) - Molecular Cell Research, vol. 1863, no. 12, pp. 2977-2992, 2016.

[102] N. Festjens, T. Vanden Berghe, and P. Vandenabeele, "Necrosis, a well-orchestrated form of cell demise: signalling cascades, important mediators and concomitant immune response," Biochimica et Biophysica Acta (BBA) - Bioenergetics, vol. 1757, no. 9-10, pp. 1371-1387, 2006.

[103] M. J. Morgan, Y. S. Kim, and Z. G. Liu, "TNF $\alpha$ and reactive oxygen species in necrotic cell death," Cell Research, vol. 18, no. 3, pp. 343-349, 2008.

[104] Y. Wen, R. Liu, N. Lin et al., "NADPH oxidase hyperactivity contributes to cardiac dysfunction and apoptosis in rats with severe experimental pancreatitis through ROSmediated MAPK signaling pathway," Oxidative Medicine and Cellular Longevity, vol. 2019, Article ID 4578175, 18 pages, 2019.

[105] J. H. Yu, J. W. Lim, K. H. Kim, T. Morio, and H. Kim, "NADPH oxidase and apoptosis in cerulein-stimulated pancreatic acinar AR42J cells," Free Radical Biology and Medicine, vol. 39, no. 5, pp. 590-602, 2005.

[106] E. Pedruzzi, C. Guichard, V. Ollivier et al., "NAD(P)H oxidase Nox-4 mediates 7-ketocholesterol-induced endoplasmic reticulum stress and apoptosis in human aortic smooth muscle cells," Molecular and Cellular Biology, vol. 24, no. 24, pp. 10703-10717, 2004

[107] W. Zhao, H. Feng, W. Sun, K. Liu, J. J. Lu, and X. Chen, “tertButyl hydroperoxide ( $\mathrm{t}-\mathrm{BHP}$ ) induced apoptosis and necroptosis in endothelial cells: roles of NOX4 and mitochondrion," Redox Biology, vol. 11, pp. 524-534, 2017.

[108] Y. S. Kim, M. J. Morgan, S. Choksi, and Z. G. Liu, “TNFinduced activation of the Nox1 NADPH oxidase and its role in the induction of necrotic cell death," Molecular Cell, vol. 26, no. 5, pp. 675-687, 2007.

[109] D.-C. Wu, P. Teismann, K. Tieu et al., "NADPH oxidase mediates oxidative stress in the 1-methyl-4-phenyl-1,2,3,6tetrahydropyridine model of Parkinson's disease," Proceedings of the National Academy of Sciences, vol. 100, no. 10, pp. 6145-6150, 2003.

[110] D. H. Choi, A. C. Cristóvão, S. Guhathakurta et al., "NADPH oxidase 1-mediated oxidative stress leads to dopamine neuron death in Parkinson's disease," Antioxidants \& Redox Signaling, vol. 16, no. 10, pp. 1033-1045, 2012.

[111] T. Seredenina, Z. Nayernia, S. Sorce et al., "Evaluation of NADPH oxidases as drug targets in a mouse model of familial amyotrophic lateral sclerosis," Free Radical Biology and Medicine, vol. 97, pp. 95-108, 2016.
[112] S. Boillée and D. W. Cleveland, "Revisiting oxidative damage in ALS: microglia, Nox, and mutant SOD1," The Journal of Clinical Investigation, vol. 118, no. 2, pp. 474-478, 2008.

[113] A. Ajayi, X. Yu, S. Lindberg, Ü. Langel, and A.-L. Ström, "Expanded ataxin-7 cause toxicity by inducing ROS production from NADPH oxidase complexes in a stable inducible spinocerebellar ataxia type 7 (SCA7) model," BMC Neuroscience, vol. 13, no. 1, p. 86, 2012.

[114] N. Y. Calingasan, K. Uchida, and G. E. Gibson, "Proteinbound acrolein: a novel marker of oxidative stress in Alzheimer's disease," Journal of Neurochemistry, vol. 72, no. 2, pp. 751-756, 1999.

[115] D. Galasko and T. J. Montine, "Biomarkers of oxidative damage and inflammation in Alzheimer's disease," Biomarkers in Medicine, vol. 4, no. 1, pp. 27-36, 2010.

[116] M. A. Smith, C. A. Rottkamp, A. Nunomura, A. K. Raina, and G. Perry, "Oxidative stress in Alzheimer's disease," Biochimica et Biophysica Acta - Molecular Basis of Disease, vol. 1502, no. 1, pp. 139-144, 2000.

[117] A. Nunomura, G. Perry, G. Aliev et al., "Oxidative damage is the earliest event in Alzheimer disease," Journal of Neuropathology \& Experimental Neurology, vol. 60, no. 8, pp. 759$767,2001$.

[118] M. A. Smith, K. Hirai, K. Hsiao et al., "Amyloid-beta deposition in Alzheimer transgenic mice is associated with oxidative stress," Journal of Neurochemistry, vol. 70, no. 5, pp. 22122215, 1998.

[119] Y. Matsuoka, M. Picciano, J. L. Francois, and K. Duff, "Fibril$\operatorname{lar} \beta$-amyloid evokes oxidative damage in a transgenic mouse model of Alzheimer's disease," Neuroscience, vol. 104, no. 3, pp. 609-613, 2001.

[120] M. A. Smith, P. L. R. Harris, L. M. Sayre, and G. Perry, "Iron accumulation in Alzheimer disease is a source of redoxgenerated free radicals," PNAS, vol. 94, no. 18, pp. 98669868, 1997.

[121] S. van Duijn, M. Bulk, S. G. van Duinen et al., "Cortical iron reflects severity of Alzheimer's disease," Journal of Alzheimer's Disease, vol. 60, no. 4, pp. 1533-1545, 2017.

[122] M. Schrag, C. Mueller, U. Oyoyo, M. A. Smith, and W. M. Kirsch, "Iron, zinc and copper in the Alzheimer's disease brain: a quantitative meta-analysis. Some insight on the influence of citation bias on scientific opinion," Progress in Neurobiology, vol. 94, no. 3, pp. 296-306, 2011.

[123] J. F. Schenck, E. A. Zimmerman, Z. Li et al., "High-field magnetic resonance imaging of brain iron in Alzheimer disease," Topics in Magnetic Resonance Imaging, vol. 17, no. 1, pp. 4150, 2006.

[124] G. Bartzokis, D. Sultzer, J. Cummings et al., "In vivo evaluation of brain iron in Alzheimer disease using magnetic resonance imaging," JAMA Psychiatry, vol. 57, no. 1, pp. 47-53, 2000.

[125] E. P. Raven, P. H. Lu, T. A. Tishler, P. Heydari, and G. Bartzokis, "Increased iron levels and decreased tissue integrity in hippocampus of Alzheimer's disease detected in vivo with magnetic resonance imaging," Journal of Alzheimer's Disease, vol. 37, no. 1, pp. 127-136, 2013.

[126] D. A. Butterfield, F. Di Domenico, A. . M. Swomley, E. Head, and M. Perluigi, "Redox proteomics analysis to decipher the neurobiology of Alzheimer-like neurodegeneration: overlaps in Down's syndrome and Alzheimer's disease brain," Biochemical Journal, vol. 463, no. 2, pp. 177-189, 2014. 
[127] B. Su, X. Wang, A. Nunomura et al., "Oxidative stress signaling in Alzheimer's disease," Current Alzheimer Research, vol. 5, no. 6, pp. 525-532, 2008.

[128] U. Kaur, P. Banerjee, A. Bir, M. Sinha, A. Biswas, and S. Chakrabarti, "Reactive oxygen species, redox signaling and neuroinflammation in Alzheimer's disease: the NF- $\kappa \mathrm{B}$ connection," Current Topics in Medicinal Chemistry, vol. 15, no. 5, pp. 446-457, 2015.

[129] C. Cheignon, M. Tomas, D. Bonnefont-Rousselot, P. Faller, C. Hureau, and F. Collin, "Oxidative stress and the amyloid beta peptide in Alzheimer's disease," Redox Biology, vol. 14, pp. 450-464, 2018.

[130] X. Wang, W. Wang, L. Li, G. Perry, H.-g. Lee, and X. Zhu, "Oxidative stress and mitochondrial dysfunction in Alzheimer's disease," Biochimica et Biophysica Acta-Molecular Basis of Disease, vol. 1842, no. 8, pp. 1240-1247, 2014.

[131] P. I. Moreira, C. Carvalho, X. Zhu, M. A. Smith, and G. Perry, "Mitochondrial dysfunction is a trigger of Alzheimer's disease pathophysiology," Biochimica et Biophysica Acta-Molecular Basis of Disease, vol. 1802, no. 1, pp. 210, 2010.

[132] S. Shimohama, H. Tanino, N. Kawakami et al., "Activation of NADPH oxidase in Alzheimer's disease brains," Biochemical and Biophysical Research Communications, vol. 273, no. 1, pp. 5-9, 2000.

[133] M. A. Ansari and S. W. Scheff, "NADPH-oxidase activation and cognition in Alzheimer disease progression," Free Radical Biology and Medicine, vol. 51, no. 1, pp. 171-178, 2011.

[134] A. J. Bruce-Keller, S. Gupta, T. E. Parrino et al., "NOX activity is increased in mild cognitive impairment," Antioxidants \& Redox Signaling, vol. 12, no. 12, pp. 1371-1382, 2010.

[135] S. Y. Kim, J. H. Moon, H. G. Lee, S. U. Kim, and Y. B. Lee, "ATP released from $\beta$-amyloid-stimulated microglia induces reactive oxygen species production in an autocrine fashion," Experimental \& Molecular Medicine, vol. 39, no. 6, pp. 820827, 2007.

[136] L. K. Parvathenani, S. Tertyshnikova, C. R. Greco, S. B. Roberts, B. Robertson, and R. Posmantur, "P2X7 mediates superoxide production in primary microglia and is upregulated in a transgenic mouse model of Alzheimer's disease," Journal of Biological Chemistry, vol. 278, no. 15, pp. 13309-13317, 2003.

[137] S. H. Choi, S. Aid, H. W. Kim, S. H. Jackson, and F. Bosetti, "Inhibition of NADPH oxidase promotes alternative and anti-inflammatory microglial activation during neuroinflammation," Journal of Neurochemistry, vol. 120, no. 2, pp. 292301, 2012.

[138] B. Qin, L. Cartier, M. Dubois-Dauphin, B. Li, L. Serrander, and K. H. Krause, "A key role for the microglial NADPH oxidase in APP-dependent killing of neurons," Neurobiology of Aging, vol. 27, no. 11, pp. 1577-1587, 2006.

[139] S. M. de la Monte and J. R. Wands, "Molecular indices of oxidative stress and mitochondrial dysfunction occur early and often progress with severity of Alzheimer's disease," Journal of Alzheimer's Disease, vol. 9, no. 2, pp. 167-181, 2006.

[140] A. J. Bruce-Keller, S. Gupta, A. G. Knight et al., "Cognitive impairment in humanized APP $\times$ PS1 mice is linked to $\mathrm{A} \beta_{1-42}$ and NOX activation," Neurobiology of Disease, vol. 44, no. 3, pp. 317-326, 2011.

[141] L. Park, P. Zhou, R. Pitstick et al., "Nox2-derived radicals contribute to neurovascular and behavioral dysfunction in mice overexpressing the amyloid precursor protein," Proceedings of the National Academy of Sciences, vol. 105, no. 4, pp. 1347-1352, 2008.

[142] E. A. Newcombe, J. Camats-Perna, M. L. Silva, N. Valmas, T. J. Huat, and R. Medeiros, "Inflammation: the link between comorbidities, genetics, and Alzheimer's disease," Journal of Neuroinflammation, vol. 15, no. 1, p. 276, 2018.

[143] P. Agostinho, R. A. Cunha, and C. Oliviera, "Neuroinflammation, oxidative stress and the pathogenesis of Alzheimers disease," Current Pharmaceutical Design, vol. 16, no. 25, pp. 2766-2778, 2010.

[144] T. Wyss-Coray and J. Rogers, "Inflammation in Alzheimer disease- a brief review of the basic science and clinical literature," Cold Spring Harbor Perspectives in Medicine, vol. 2, no. 1, 2012.

[145] M. L. Block, "NADPH oxidase as a therapeutic target in Alzheimer's disease," BMC Neuroscience, vol. 9, no. S2, 2008Supplement 2, 2008.

[146] R. P. Brandes, N. Weissman, and K. Schröder, "Nox family NADPH oxidases: molecular mechanisms of activation," Free Radical Biology in Medicine, vol. 76, pp. 208-226, 2014.

[147] S. K. McCann and C. L. Roulston, "NADPH oxidase as a therapeutic target for neuroprotection against ischaemic stroke: future perspectives," Brain Sciences, vol. 3, no. 4, pp. 561598, 2013.

[148] G. Teixeira, C. Szyndralewiez, S. Molango et al., "Therapeutic potential of NADPH oxidase 1/4 inhibitors," British Journal of Pharmacology, vol. 174, no. 12, pp. 1647-1669, 2017.

[149] B. A. 't. Hart, S. Copray, and I. Philippens, "Apocynin, a low molecular oral treatment for neurodegenerative disease," BioMed Research International, vol. 2014, Article ID 298020, 6 pages, 2014.

[150] M. E. Lull, S. Levesque, M. J. Surace, and M. L. Block, "Chronic apocynin treatment attenuates beta amyloid plaque size and microglial number in $\mathrm{hAPP}(751)_{\mathrm{SL}}$ mice," PLoS One, vol. 6, no. 5, article e20153, 2011.

[151] E. Joseph, D. M. A. Villalobos-Acosta, M. A. Torres-Ramos et al., "Neuroprotective effects of apocynin and galantamine during the chronic administration of scopolamine in an Alzheimer's disease model," Journal of Molecular Neuroscience, vol. 70, no. 2, pp. 180-193, 2020.

[152] S. Barua, J. Y. Kim, M. A. Yenari, and J. E. Lee, "The role of NOX inhibitors in neurodegenerative diseases," IBRO Reports, vol. 7, pp. 59-69, 2019.

[153] R. de la Torre, S. de Sola, G. Hernandez et al., "Safety and efficacy of cognitive training plus epigallocatechin-3-gallate in young adults with Down's syndrome (TESDAD): a doubleblind, randomised, placebo-controlled, phase 2 trial," The Lancet Neurology, vol. 15, no. 8, pp. 801-810, 2016.

[154] R. S. Turner, R. G. Thomas, S. Craft et al., "A randomized, double-blind, placebo-controlled trial of resveratrol for Alzheimer disease," Neurology, vol. 85, no. 16, pp. 1383-1391, 2015.

[155] C. W. Zhu, H. Grossman, J. Neugroschl et al., "A randomized, double-blind, placebo-controlled trial of resveratrol with glucose and malate (RGM) to slow the progression of Alzheimer's disease: a pilot study," Translational Research \& Clinical Interventions, vol. 4, no. 1, pp. 609-616, 2018.

[156] R. Remington, C. Bechtel, D. Larsen et al., "A phase II randomized clinical trial of a nutritional formulation for cognition and mood in Alzheimer's disease," Journal of Alzheimer's Disease, vol. 45, no. 2, pp. 395-405, 2015. 
[157] R. Remington, C. Bechtel, D. Larsen et al., "Maintenance of cognitive performance and mood for individuals with Alzheimer's disease following consumption of a nutraceutical formulation: a one-year, open-label study," Journal of Alzheimer's Disease, vol. 51, no. 4, pp. 991-995, 2016.

[158] J. M. Ringman, S. A. Frautschy, E. Teng et al., "Oral curcumin for Alzheimer's disease: tolerability and efficacy in a 24-week randomized, double blind, placebo-controlled study," Alzheimer's Research \& Therapy, vol. 4, no. 5, p. 43, 2012.

[159] S. T. DeKosky, J. D. Williamson, A. L. Fitzpatrick et al., "Ginkgo biloba for prevention of dementia: a randomized controlled trial," JAMA, vol. 300, no. 19, pp. 2253-2262, 2008.

[160] B. E. Snitz, E. S. O'Meara, M. C. Carlson et al., "Ginkgo biloba for preventing cognitive decline in older adults: a randomized trial," JAMA, vol. 302, no. 24, pp. 2663-2670, 2009.

[161] L. H. Kuller, D. G. Ives, A. L. Fitzpatrick et al., "Does Ginkgo biloba reduce the risk of cardiovascular events?," Circulation: Cardiovascular Quality and Outcomes, vol. 3, no. 1, pp. 4147, 2010.

[162] B. Vellas, N. Coley, P.-J. Ousset et al., "Long-term use of standardised ginkgo biloba extract for the prevention of Alzheimer's disease (GuidAge): a randomised placebo-controlled trial," The Lancet Neurology, vol. 11, no. 10, pp. 851-859, 2012.

[163] C. Singer, R. E. Tractenberg, J. Kaye et al., "A multicenter, placebo-controlled trial of melatonin for sleep disturbance in Alzheimer's disease," Sleep, vol. 26, no. 7, pp. 893-901, 2003. 